\title{
Aproximación al contexto de producción de la obra pictórica "Milagro de la Virgen de Guápulo en su Santuario", atribuida a Miguel de Santiago (Siglo XVII)
}

\author{
Martha Elizabeth Romero, Michelle Carolina Mármol, Carlos Andrés Vásquez, Fernando \\ Espinoza, Rita del Consuelo Díaz, Edgar Santamaría Robles
}

\begin{abstract}
Resumen: La obra "Milagro de la Virgen de Guápulo en su Santuario" fue estudiada como un registro histórico de la época desde una perspectiva multidisciplinaria donde convergen la historia del arte, el arte y las ciencias experimentales, para comprender los aspectos tecnológicos involucrados en su factura. Con el uso combinado de técnicas analíticas no invasivas como IRFC y FRX y la mínima extracción de muestras para análisis por FTIR y MEB-EDX se identificaron diez pigmentos/colorantes y se dilucidaron las secuencias técnico pictóricas empleadas por su artífice. El leguaje simbólico, la calidad y costo de los materiales usados, así como la valía del ejecutante determinaron el algo prestigio y dignidad de la obra.
\end{abstract}

Palabras clave: Miguel de Santiago, pigmentos, FRX, FTIR-ATR, IRFC, MEB-EDX, técnica pictórica, sección transversal

\section{Approach to the production context of the paint "Milagro de la Virgen de Guápulo en su Santuario", attributed to Miguel de Santiago (17th century)}

Abstract: The work "Milagro de la Virgen de Guápulo en su Santuario " was studied, as a historical record, from a multidisciplinary perspective. Art history, art and experimental sciences converged in this study to understand the technological aspects involved in its manufacture. With the combined use of non-invasive analytical techniques such as IRFC and FRX, and the minimal extraction of samples for analysis by FTIR and SEM-EDS, ten pigments/colorants were identified and the technical pictorial sequences used by the artist were elucidated. The symbolic language in use, the quality and cost of the materials involved, as well as the value of the individual artist who created it determined the prestige and dignity of the work.

Keyword: Miguel de Santiago, pigments, XRF, FTIR-ATR, IRFC, SEM-EDS, painting technique, cross section

\section{Aproximação ao contexto de produção da obra pictórica "Milagre da Virgem de Guápulo no seu Santuário", atribuída a Miguel de Santiago (séc. XVII)}

Resumo: A obra "Milagre da Virgem de Guápulo no seu Santuário" foi estudada como um registo histórico da época numa perspetiva multidisciplinar onde convergem a história da arte, a arte e as ciências experimentais, para compreender os aspetos tecnológicos envolvidos na sua obra. Com o uso combinado de técnicas analíticas não invasivas como IRFC e XRF e a extração mínima de amostras para análise por FTIR e SEM-EDX, identificaram-se dez pigmentos / corantes e elucidaram-se as sequências técnico-pictóricas empregues pelo seu artista. A linguagem simbólica, a qualidade e o custo dos materiais utilizados, bem como o valor do executante determinam o prestígio e a dignidade da obra.

Palavras-chave: Miguel de Santiago, pigmentos, XRF, FTIR-ATR, IRFC, SEM-EDX, técnica pictórica, seção transversal 


\section{Introducción}

El arte es un lenguaje simbólico creado por un autor, condicionado por su entorno social-cultural y ambiental, es una expresión de la sensibilidad humana, ejecutado con una finalidad estética y también comunicativa en la que converge un entramado de múltiples aspectos formales y subjetivos (Benjamin 1936; Hauser 1974).

En este sentido, las obras pictóricas son un reflejo de los acontecimientos políticos, sociales o culturales de la época en que se enmarca su producción y su estudio debe afrontarse desde un enfoque transdisciplinar, con la mirada abierta, observando la totalidad de los aspectos desde nuestra limitación humana, para desde ahí generar conocimientos más significativos y que trasciendan una visión reduccionista, tal como lo menciona Edgar Morín en sus teorías. (Morin 1990).

En el estudio de los materiales y técnicas en la pintura colonial andina cabe resaltar el trabajo interdisciplinario y la metodología desarrollada por Siracusano y su equipo, quienes conciben la dimensión material de los objetos artísticos como un documento histórico de las prácticas pasadas. (Siracusano 2005) En el caso del Ecuador, tradicionalmente las obras pictóricas se han estudiado siguiendo criterios estéticos, históricos, culturales y de conservación en forma aislada. Pero estudios recientes han presentado nuevas perspectivas para el análisis del arte colonial y decimonónico, resaltando la importancia de la materialidad y han proporcionado nueva información sobre la circulación, intercambio y comercio de materiales (Estebaranz 2011; Webster 2016; Webster 2017; Bermeo 2019). Lo cual evidencia, que hasta el momento no ha existido un diálogo entre la investigación documental y teoría de la historia del arte y la investigación experimental, que permita profundizar en el conocimiento de las prácticas culturales asociadas a su producción.

Por otro lado, la naturaleza única e invaluable de las obras pictóricas impone varias restricciones al uso de las técnicas analíticas a emplearse, especialmente cuando se requiere extraer muestras, las cuales siempre están restringidas en número y localización. Tradicionalmente, el primer paso para su análisis es la preparación del corte transversal de la muestra, seguido del análisis microquímico por medio de técnicas analíticas convencionales como: microscopía óptica, espectroscopia de energía dispersiva de rayos $\mathrm{X}$ y espectroscopía Infrarroja con transformadas de Fourier (La Russa et al. 2009; Duran et al. 2010; Doleżyńska-Sewerniak, E y Klisińska-Kopacz, A. 2019).

El desarrollo de equipos de análisis no invasivo como el sistema de imágenes multiespectrales o el analizador de fluorescencia de rayos X (FRX), facilitan el desplazamiento del equipo hasta la obra y un mayor número de mediciones sin necesidad de la toma de muestras (DoleżyńskaSewerniak, E \& Klisińska-Kopacz, A. 2019; Barbu et al. 2016; Gargano, M. et al. 2020). No obstante, estas técnicas no proporcionan información de la totalidad de los estratos que conforman la obra, lo que restringe el discernimiento de aspectos relacionados con las secuencias de elecciones y operaciones que ejecutó el artista. Por lo que sin lugar a dudas, las técnicas no invasivas no pueden reemplazar aquellas que demandan la extracción de muestras, y viceversa, de modo que es preciso combinarlas para conseguir la mayor cantidad de información con la menor cantidad de muestras extraídas.

El presente estudio pone a prueba una metodología transdisciplinar donde convergen las ciencias experimentales, el arte y la historia del arte, para indagar sobre el contexto de producción de la obra pictórica "Milagro de la Virgen de Guápulo en su Santuario", atribuida a Miguel de Santiago (Siglo XVII). Parte del análisis de las representaciones simbólicas que grafican el mundo social en el que se desarrolló el autor de la obra; para continuar con el análisis de la materialidad con el uso combinado de técnicas no invasivas y la mínima extracción de micro muestras para conocer sobre los materiales, elecciones técnicas y acciones físicas que se dieron en el proceso de elaboración. Finalmente, los resultados obtenidos se contrastaran con los manuales de pintura de época y otros trabajos de investigación sobre el uso de pigmentos en la región andina, situar la obra en un contexto más amplio.

\section{Materiales y métodos}

Para el desarrollo de esta investigación, fue necesario diseñar y poner a punto una metodología que involucre la transdisciplina a lo largo de todo el proceso, donde se practique un diálogo constante entre la historia del arte y las ciencias experimentales, como dos ramas del saber que se complementan mutuamente, con la finalidad de aportar al conocimiento de las prácticas culturales involucradas en la ejecución de la obra pictórica.

La metodología analítica da preferencia al uso de técnicas no destructivas como la espectroscopia Infrarrojo Falso Color (IRFC) y la espectroscopia de florescencia de rayos $\mathrm{X}$ (FRX); y la toma de 3 micromuestras para el análisis de los estratos por espectroscopia dispersiva de rayos $X$ acoplado a un microscopia electrónica de barrido (MEB-EDX) y espectroscopia infrarroja infrarroja con transformadas de Fourier y ATR (FTIR-ATR).

El análisis prospectivo Infrarrojo Falso Color (IRFC) es un método móvil y no invasivo que utiliza la superposición de ondas infrarrojas al espectro visible, para alterar el color y dar un falso tono a la gama visible de color, con el uso de herramientas digitales de imagen. Se usó una cámara réflex Nikon D800 modificada, filtros infrarrojo de $1000 \mathrm{~nm}$ y visible de $540 \mathrm{~nm}$. Se acondicionó un ambiente oscuro y espacioso, cuya iluminación se obtuvo por una fuente incandescente externa. El tratamiento de la imagen se realizó con un software de edición de imágenes. (Cosentino 2013; Teke et al. 2011) 
Fluorescencia de Rayos X (FRX) Se utilizó un equipo portátil de fluorescencia de rayos " $\mathrm{X}$ " (FRX), marca Bruker Tracer modelo III SD, para determinar la composición elemental de los pigmentos. Se colocó el equipo directamente sobre el color a analizar de forma perpendicular. Las lecturas se tomaron por 180 segundos, sin usar filtros y los espectros se interpretaron de manera cualitativa, usando el software ARTAX.

Espectroscopía infrarroja con transformadas de Fourier y reflactancia total atenuada (FTIR-ATR). Los materiales de naturaleza orgánica e inorgánica como pigmentos, colorantes naturales y aglutinantes se identificaron por FTIRATR. Esta técnica se realiza con un equipo de espectroscopia infrarroja con Transformadas de Fourier marca Jasco Modelo 4200 utilizando un accesorio de Atenuación Total Reflejada ATR. El rango de lectura es de 550 a $4000 \mathrm{~cm}-1$. Las lecturas se realizan en porcentaje de transmitancia.

El microscopio electrónico de barrido utilizado tienen una sonda de energía dispersiva para el microanálisis puntual con rayos $x$, se emplea para la observación de estructuras con el fin de lograr una caracterización química elemental o para definir morfología característica. Las condiciones empleadas fueron a una presión de $55 \mathrm{~Pa}$., a una distancia de trabajo de $10 \mathrm{~mm}$, una energía de 20.0kW. Se empleó para la obtención de imagen un detector de electrones retrodispersados y para la composición química un detector de rayos $\mathrm{X}$.

\section{Contexto histórico y cultural}

La obra en estudio no tiene referencia iconográfica de grabados u obras europeas, es una creación del autor y responde a un registro histórico, sucedido en un tiempo y espacio determinados, a través del cual se pone de relieve un acontecimiento altamente simbólico, que involucró a los poderes religiosos y civiles locales. Ocurrió en la iglesia del monasterio de Guápulo, el cual fue emplazado estratégicamente hacia la entrada de la Amazonía e instaurado allí para ejercer el poder político y religioso sobre la población indígena establecida en ese sector y sus alrededores (Salgado Gómez 1997: 37). La ceremonia transcurrió a los pies del Altar de la Virgen de Guápulo, imagen que debido a los constantes "favores y milagros obrados", fue objeto de un mayor y más intenso culto, por lo que indudablemente jugó un papel relevante en la evangelización de la población nativa local, a quienes se debía transmitir los dogmas, las verdades teológicas y toda la doctrina de la iglesia contrareformista, facilitando su proceso de adoctrinamiento.

Por lo tanto, la escena responde a una época, donde los símbolos propagados por la Contrarreforma fueron la fuente de representaciones visuales, que buscaban legitimar no solo una religión unificadora reformada, la católica, sino además el poder dinástico real de los Austrias, quienes basaron su modelo de regencia en la religión católica (Pascual Chenel 2013). Elementos que determinaron el orden político de una sociedad colonial, que fue influenciada con el uso de imágenes religiosas que tenían la capacidad de expresar sentimientos y pasiones, pero también formas de espiritualidad, como la fe, la paz, la misericordia y que inspiraron el fervor religioso (Terán 2009).

La ejecución de la obra "El Milagro de la Virgen de Guápulo" rompe una forma de trabajo habitual de los pintores de la época y pone de manifiesto, la madurez artística, la creatividad, la capacidad de síntesis y la armonización de las figuras que están siendo plasmadas sobre el lienzo y que representan una ceremonia religiosa de alto simbólismo y que es captada con lujo de detalle, al punto de individualizar a los personajes, por Miguel de Santiago. Personaje quien, siendo hijo natural de madre y padre indígenas, fue declarado maestro pintor a una edad temprana (23 a 25 años) y fue capaz de mantener un obrador con suficiente cantidad de oficiales, y abastecido de variados materiales y herramientas para satisfacer los encargos de las órdenes religiosas dentro y fuera del territorio de la Audiencia de Quito (Estebaranz 2013; Estebaranz 2011).

Si analizamos la obra pictórica desde su lenguaje simbólico y la leyenda que reza al pie del cuadro ${ }^{[2]}$ [figura 1], podemos admirar en primer lugar el poder divino representado por la Virgen María en su nicho central superior; a cuyos pies se representan los diversos estamentos sociales diferenciados, reflejo de la sociedad imperante de la época. Tanto las autoridades que ostentan el poder civil y religioso, ocupan los sitiales de mayor privilegio y más próximos al altar, entre las que están presentes el Obispo (Agustín Duarte) y un grupo de autoridades religiosas; luego se representaron a las autoridades civiles y administrativas de la Audiencia de Quito y del Cabildo, liderados por el presidente don Martín de Arriola, con vestimenta larga de color negro y golilla blanca, propio de los oidores y demás autoridades, quienes estuvieron ubicados un escalón más abajo. Separados por una balaustrada corrida que divide el área del altar mayor, estuvieron los demás personajes civiles y religiosos que asistieron a la ceremonia. En la primera fila los religiosos vinculados al conocimiento (universidades) identificados por su vestimenta. Le siguen en orden de importancia los clérigos de las diferentes órdenes religiosas y finalmente, los demás personajes de elite social local. Mientras que al frente, se ubica un escaso número de mujeres recubiertas con velos negros (De la Puerta 2008; Vargas 1959), de las que no se puede definir su identidad social, pero que debieron estar estrechamente relacionadas con el culto a la Virgen y el servicio de la iglesia (beatas).

\section{Caracterización de materiales}

En la [tabla 1] se exponen los pigmentos y colorantes identificados por las diferentes técnicas analíticas.

\section{-Preparación del soporte}

Está formada por tres estratos. La primera capa de la preparación estaba reducida a ligeras manos de cola animal 

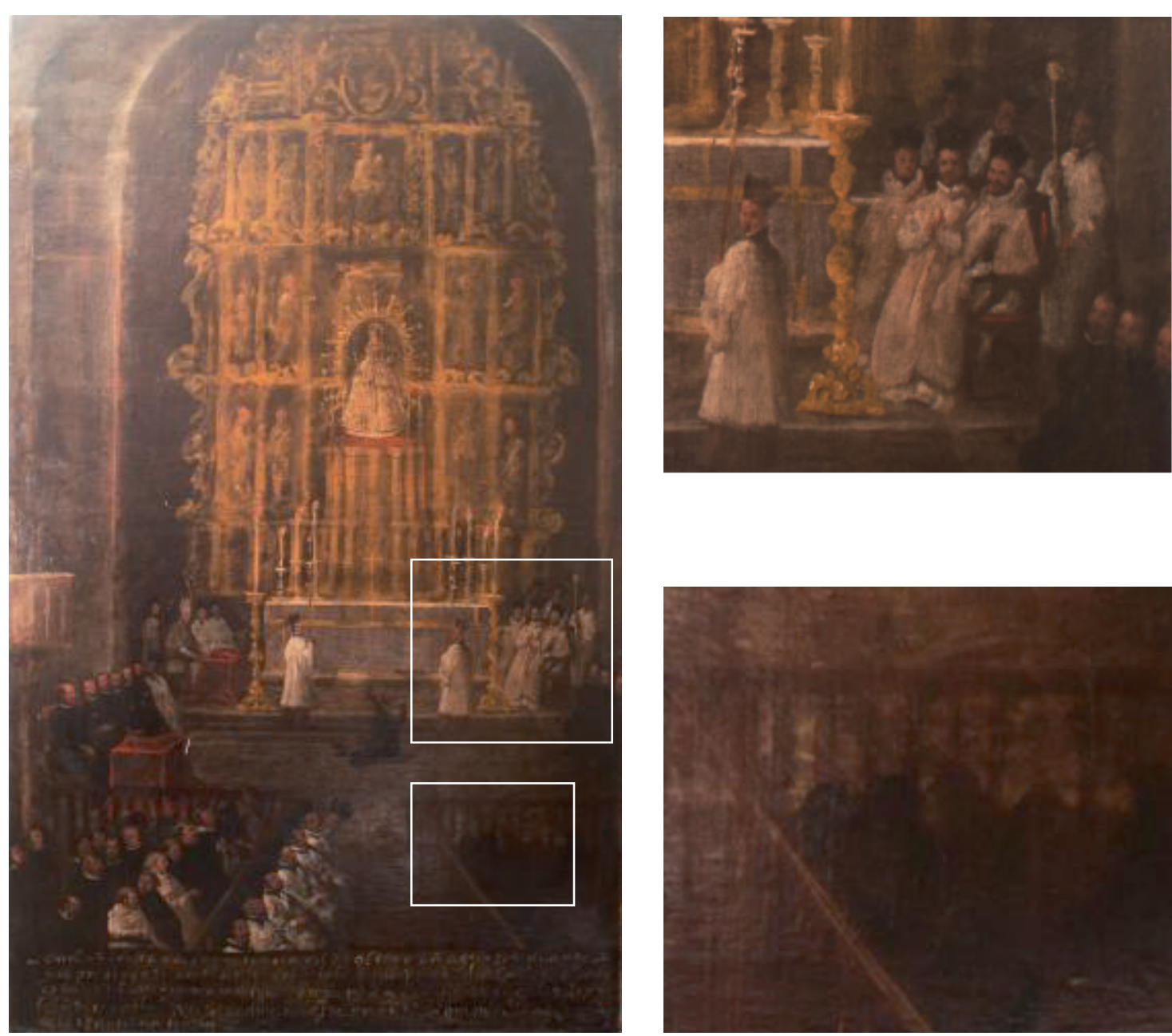

Figura 1.- El milagro de la virgen en el santuario. Autor: Carlos Vásquez, INPC..

\begin{tabular}{|c|c|c|c|c|}
\hline \multirow{2}{*}{ Colores } & \multicolumn{3}{|c|}{ Técnicas de Análisis } & \multirow{2}{*}{ Materiales } \\
\hline & IRFC & FTIR-ATR & FRX/SEM & \\
\hline \multirow{3}{*}{ Amarillo } & Pardo & $\begin{array}{c}3540.67 \mathrm{~cm}^{-1}(\mathrm{~Pb}-\mathrm{O}) \\
1394.28 \mathrm{~cm}^{-1}(\mathrm{O}=\mathrm{CO})\end{array}$ & $\mathrm{Pb}$ & Masicote \\
\hline & Verde lechoso & $\begin{array}{c}1644 \mathrm{~cm}^{-1}(\mathrm{O}=\mathrm{C}) \\
1459 \mathrm{~cm}^{-1}(\mathrm{O}=\mathrm{CO}) \\
1009 \mathrm{~cm}^{-1}(\mathrm{C}-\mathrm{O})\end{array}$ & - & Gualda/ancorca/arzica \\
\hline & Café amarillento & $\begin{array}{c}1000 \mathrm{~cm}^{-1}(\mathrm{Fe}-\mathrm{O}) \\
915-890 \mathrm{~cm}^{-1}(\mathrm{Fe}-\mathrm{O}) \\
780 \mathrm{~cm}^{-1}\end{array}$ & $\mathrm{Fe}$ & Siena natural \\
\hline \multirow{4}{*}{ Rojo } & Café Rojizo & $1023.05 \mathrm{~cm}^{-1}(\mathrm{Fe}-\mathrm{O})$ & $\mathrm{Fe}$ & Ocre Rojizo \\
\hline & Anaranjado & $\begin{array}{c}3821.26 \mathrm{~cm}^{-1}(\mathrm{~Pb}-\mathrm{O}) \\
1405.85 \mathrm{~cm}^{-1}(\mathrm{O}=\mathrm{CO})\end{array}$ & $\mathrm{Pb}$ & Minio \\
\hline & Rojo & $\begin{array}{c}3747.01 \mathrm{~cm}^{-1}(\mathrm{Hg}-\mathrm{S}) \\
1018.23 \mathrm{~cm}^{-1}(\mathrm{~S}-\mathrm{S})\end{array}$ & $\mathrm{Hg}, \mathrm{S}$ & Cinabrio/Bermellón \\
\hline & Rosaceo verdoso & $\begin{array}{c}1627 \mathrm{~cm}^{-1}(\mathrm{O}=\mathrm{C}) 1453 \mathrm{~cm}^{-1}(\mathrm{O}=\mathrm{CO}) \\
1333 \mathrm{~cm}^{-1}(\mathrm{HOC}=\mathrm{O}) \\
1005 \mathrm{~cm}^{-1}(\mathrm{C}-\mathrm{O})\end{array}$ & - & Carmín \\
\hline Café & Café Rojizo & $1021.12 \mathrm{~cm}^{-1}(\mathrm{Fe}-\mathrm{O})$ & $\mathrm{Fe}$ & Siena Tostada \\
\hline Negro & Negro & - & C & Negro de humo \\
\hline Blanco & Blanco & $\begin{array}{c}3534 \mathrm{~cm}^{-1}(\mathrm{~Pb}-\mathrm{O}) \\
1725 \mathrm{~cm}^{-1}(\mathrm{HO}-\mathrm{C}=\mathrm{O}) \\
1391 \mathrm{~cm}^{-1} \mathrm{C}-\mathrm{O} \text { y } 839 \mathrm{~cm}^{-1}(\mathrm{C}-\mathrm{C})\end{array}$ & $\mathrm{Pb}$ & Blanco de plomo \\
\hline
\end{tabular}

Tabla 1.- Resultados de los análisis globales de la obra. Autor: Martha Romero, INPC. 
cubierta de una imprimación coloreada de doble capa. El análisis por FTIR develó que la primera capa está compuesta principalmente de tierra de sombra natural y blanco de plomo usado como secante. El segundo estrato es de mayor tamaño y es de siena tostada (Fe2O3) con minio (Pb3O4) como secante.

\section{Pigmentos y colorantes}

Tres tipos de pigmentos/colorantes amarillos fueron usados por el maestro en la obra [figura 2a]: ocre amarillo $\left(\mathrm{Fe}_{2} \mathrm{O}_{3} \cdot \mathrm{H}_{2} \mathrm{O}\right)$, masicote $(\mathrm{PbO})$ y laca de gualda. Las imágenes IRFC manifiestan un color verde lechoso en la mayor parte de la obra, consistente con la laca de gualda, mientras que en las molduras e iluminaciones del retablo son visibles ciertas tonalidades que sugieren la presencia de ocre y masicote [figura $2 b$ ].

Los espectros FTIR de la fase orgánica, consintieron la identificación de luteína, un flavonoide [1] responsable del color del gualda también conocido como ancorca o arzica, detectado por las bandas de absorción debidas a grupos carbonilos de aldehídos $(\mathrm{HO}-\mathrm{C}=\mathrm{O})$ en $1732 \mathrm{~cm}^{-1}$, cetonas $(\mathrm{O}=\mathrm{C})$ en $1610 \mathrm{~cm}^{-1}$, éster $(\mathrm{O}=\mathrm{CO})$ a 1320 y 1230 $\mathrm{cm}^{-1}$ y alcoholes (C-O) entre 1098 a $1009 \mathrm{~cm}^{-1}$ [figura 2c]. (lacopo et al. 2020)

La fase inorgánica soluble en agua, mantiene algunas sales suspendidas, que en concentraciones adecuadas permitió identificar los óxidos de hierro y de plomo, quien al estar más abundante fue identificado en el color dorado, con picos a $1730 \mathrm{~cm}^{-1}$ y $1400 \mathrm{~cm}^{-1}(\mathrm{~Pb}-\mathrm{O})$ [figura $2 d]$.

Cuatro pigmentos/colorantes rojos fueron usados en los encarne, telas, en la base del nicho de la virgen y en las llamas de los cirios: carmín, siena tostada $\left(\mathrm{Fe}_{2} \mathrm{O}_{3}+\mathrm{MnO}_{2}\right)$, ocre rojizo $\left(\mathrm{Fe}_{2} \mathrm{O}_{3}\right)$ y cinabrio/bermellón ( $\mathrm{HgS}$ ) [figura 3a, 3c]. En las imágenes IRFC se puede apreciar la ubicación de los materiales y la forma de uso. No obstante, solo los análisis instrumentales permitieron un mayor discernimiento. [figura 3b, 3d]

La FTIR-ATR permitió constatar la presencia de carmín en
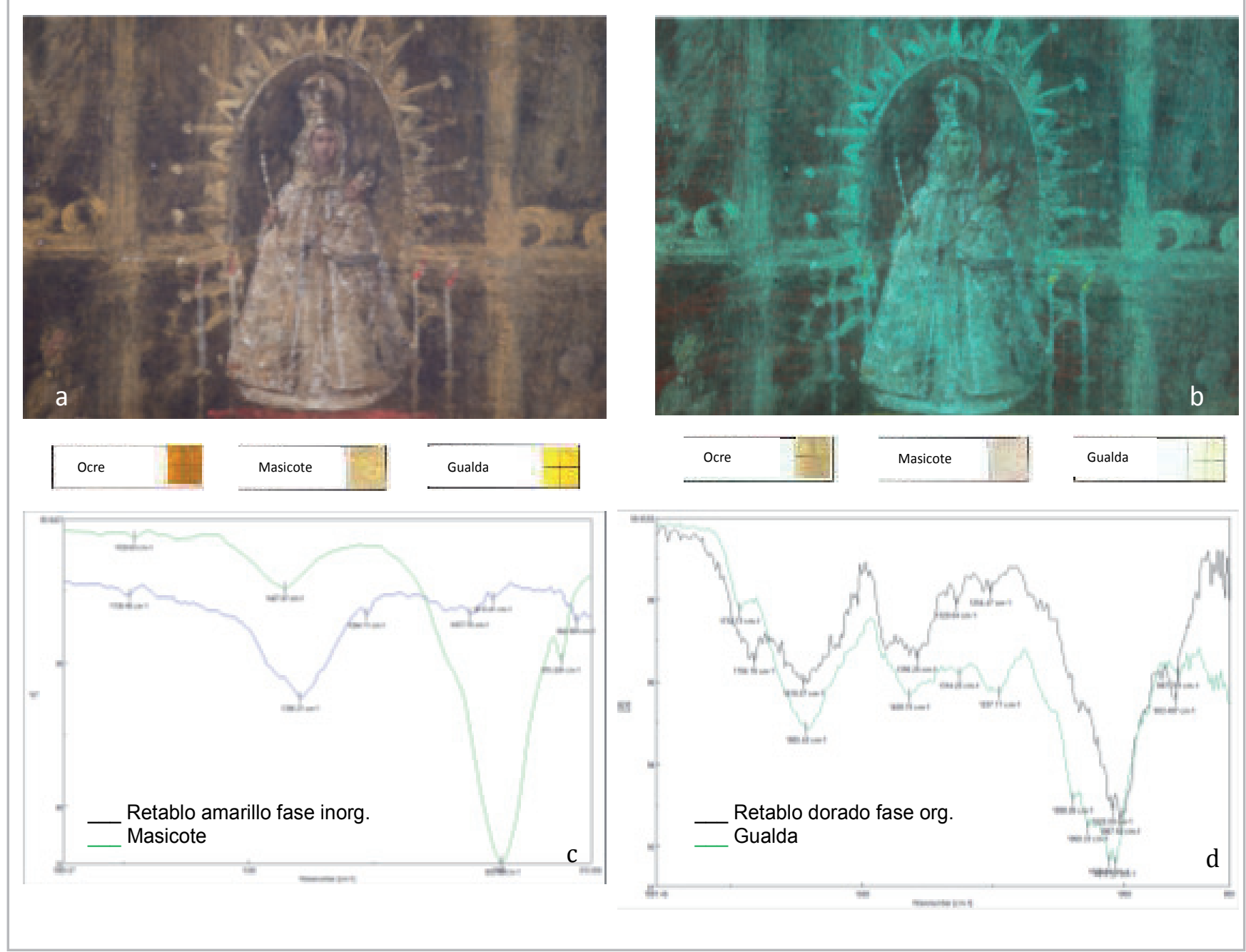

Figura 2.- Detalle, a) Imagen virgen en el retablo con VIS, b) Imagen virgen en el retablo IRFC, c) Espectro FTIR-ATR del retablo amarillo vs estándar de masicote, d) Espectro FTIR-ATR de la muestra vs estándar de gualda. Autores: Fernando Espinoza, Michelle Mármol y Carlos Vásquez, INPC. 


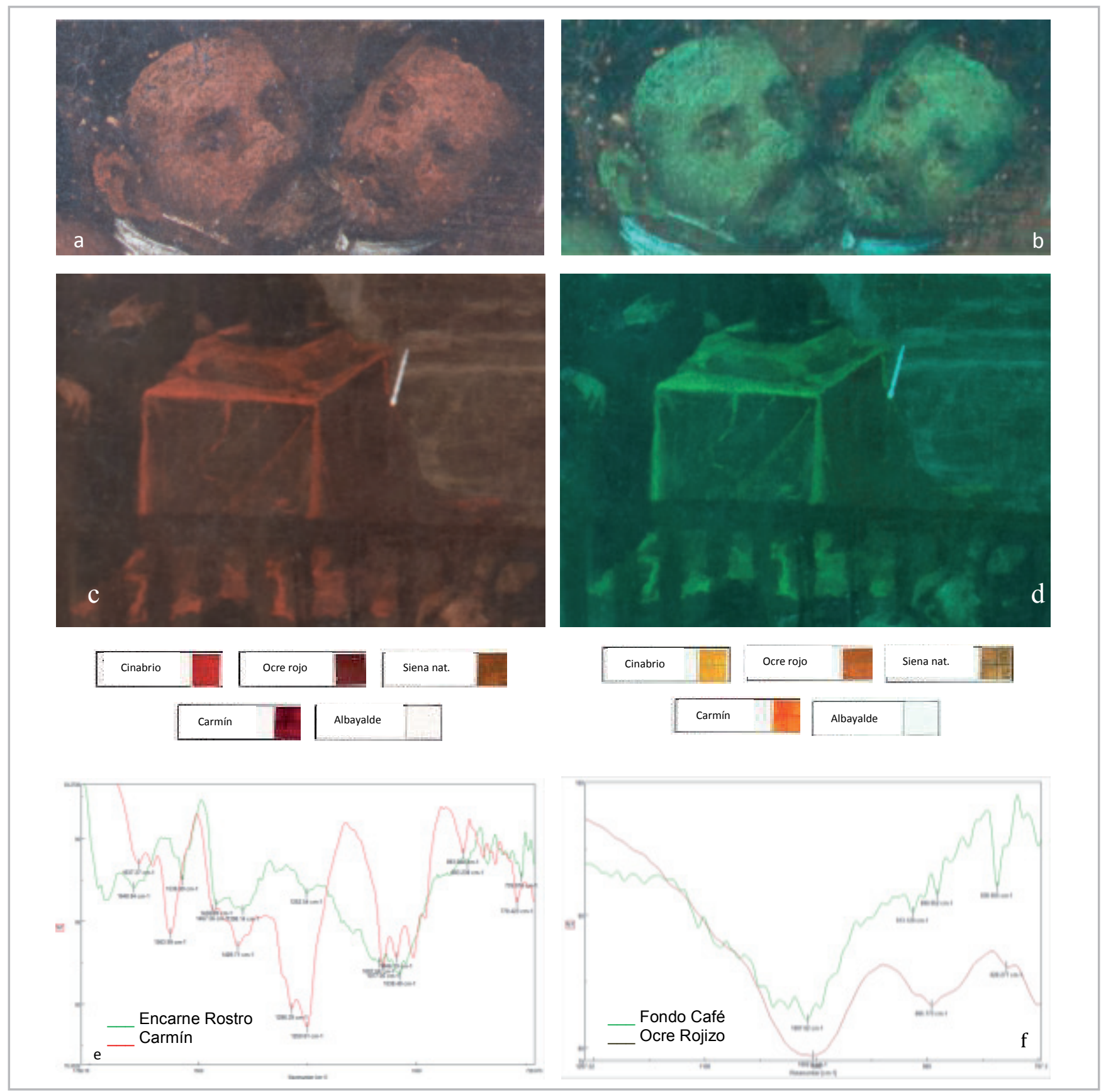

Figura 3.- Detalle, a) Encarne de sacerdotes con VIS, b) Encarne de sacerdotes IRFC, c) Detalle mantel del sitio de análisis con VIS, d) Detalle mantel del sitio de análisis IRFC. e) Espectro FTIR-ATR de encarne vs carmín, f) Espectro FTIR-ATR de la muestra de fondo vs estándar de siena natural. Autores: Fernando Espinoza, Michelle Mármol y Carlos Vásquez, INPC.

encarnes, al identificar el ácido carmínico, cuyas bandas de absorción corresponden a grupos cetonas $(\mathrm{O}=\mathrm{C})$ en $1627 \mathrm{~cm}^{-1}$, grupos éster $(\mathrm{O}=\mathrm{CO})$ a $1453 \mathrm{~cm}^{-1}$, ácido carboxílico $(\mathrm{HO}-\mathrm{C}=\mathrm{O})$ a $1333 \mathrm{~cm}^{-1}$ y alcoholes (C-O) en $1005 \mathrm{~cm}^{-1}$ [figura 3e] (Carbó et al. 1996); y ocre rojizo, por las zonas del espectro entre 1009 a $800 \mathrm{~cm}^{-1}$ donde resaltan variaciones de posición por efecto de deflexión y torsión entre las moléculas, propagando algunas bandas más que otras. [figura $3 \mathrm{f}$ ].

El análisis por FRX del sector de las telas rojas y los encarnes, reveló abundancia de hierro (Fe) acompañado de plomo $(\mathrm{Pb})$, mercurio $(\mathrm{Hg})$ y manganeso $(\mathrm{Mn})$ en menor cantidad, confirmando y esclareciendo el uso de una mezcla de minio $\left(\mathrm{Pb}_{3} \mathrm{O}_{4}\right)$, cinabrio $(\mathrm{HgS})$ y siena tostada [figura 3g].

Un análisis de mapeo químico en una sección transversal obtenida del encane por MEB-EDX de los encarnes, reveló presencia de hierro (Fe) acompañado de plomo (Pb), mercurio $(\mathrm{Hg})$ y manganeso $(\mathrm{Mn})$ en menor cantidad, confirmando y esclareciendo el uso de una mezcla de albayalde $\left(\mathrm{PbCO}_{3} \cdot \mathrm{Pb}(\mathrm{OH})_{2}\right)$, cinabrio $(\mathrm{HgS})$ y siena tostada [figura 4]. 
Si Ka1
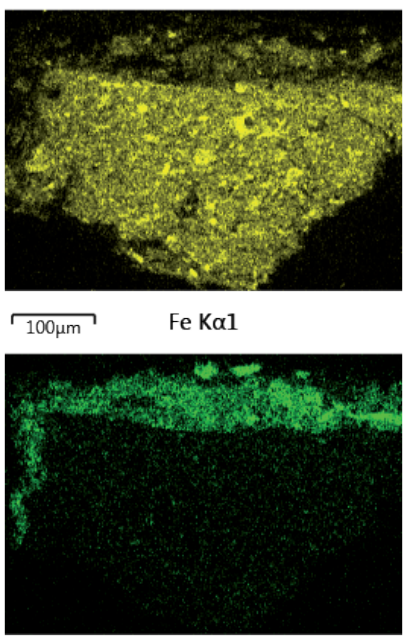

$\longdiv { 1 0 0 \mu \mathrm { m } }$

Figura 4.- Sección transversal de encarne en imagen visible $y$ mapeo químico. Autores: Michelle Mármol y Martha Romero, INPC.

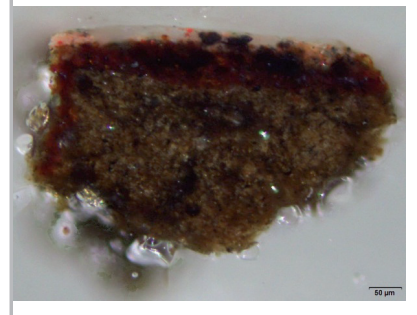

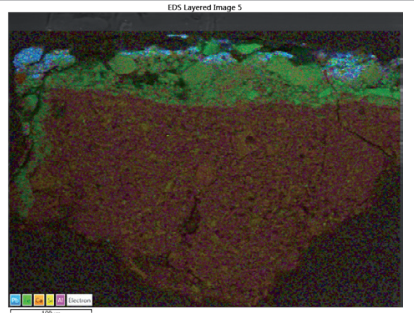

$\mathrm{Pb} M \alpha 1$

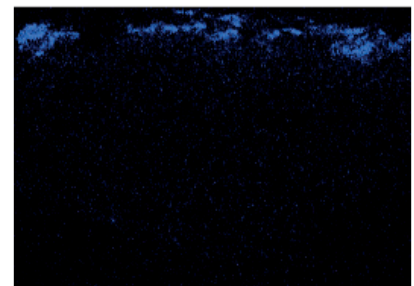

$\longdiv { 1 0 0 \mu \mathrm { m } } \quad \mathrm { Hg } \mathrm { M } \alpha 1$

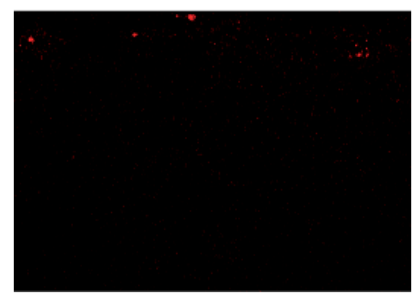

$\longdiv { 1 0 0 \mu \mathrm { m } }$

\section{Los negros, blancos y cafés}

La composición cromática de este detalle está conformada por colores negros, blancos y cafés [figura 5a], mismos que a través de las imágenes IRFC se aproxima al negro de humo, blanco de plomo y siena natural [figura 5b]. Datos que fueron corroborados por las técnicas instrumentales. El albayaldeesidentificado por FTIR, sus picos representativos están a $3534 \mathrm{~cm}^{-1}(\mathrm{~Pb}-\mathrm{O}), 1725 \mathrm{~cm}^{-1}(\mathrm{HO}-\mathrm{C}=\mathrm{O}), 1391 \mathrm{~cm}^{-1}(\mathrm{C}$ O) y y $839 \mathrm{~cm}^{-1}$ (C-C). [figura $5 \mathrm{c}$ ] La siena natural se diferencia de los ocres rojizos por los picos de las transiciones de deflexión y tensión del enlace Fe-O alrededor de $1000 \mathrm{~cm}^{-1}$, $915-890 \mathrm{~cm}^{-1}$ y $780 \mathrm{~cm}^{-1}$. [figura $5 \mathrm{~d}$ ] El negro de carbón o de humo no puede ser detectado por FTIR, debido a que este material absorbe la radiación infrarroja.

Resumiendo, Miguel de Santiago usó diez pigmentos y colorantes. De estos, siete son pigmentos de naturaleza inorgánica como el masicote, ocre amarillo, ocre rojizo, minio, cinabrio/bermellón, siena tostada, siena natural y blanco de plomo; y tres son colorantes orgánicos, carmín, gualda y negro de humo.

\section{Recursos técnico pictóricos}

El efecto logrado en la ambientación del área y configuración del retablo, es el resultado del trabajo

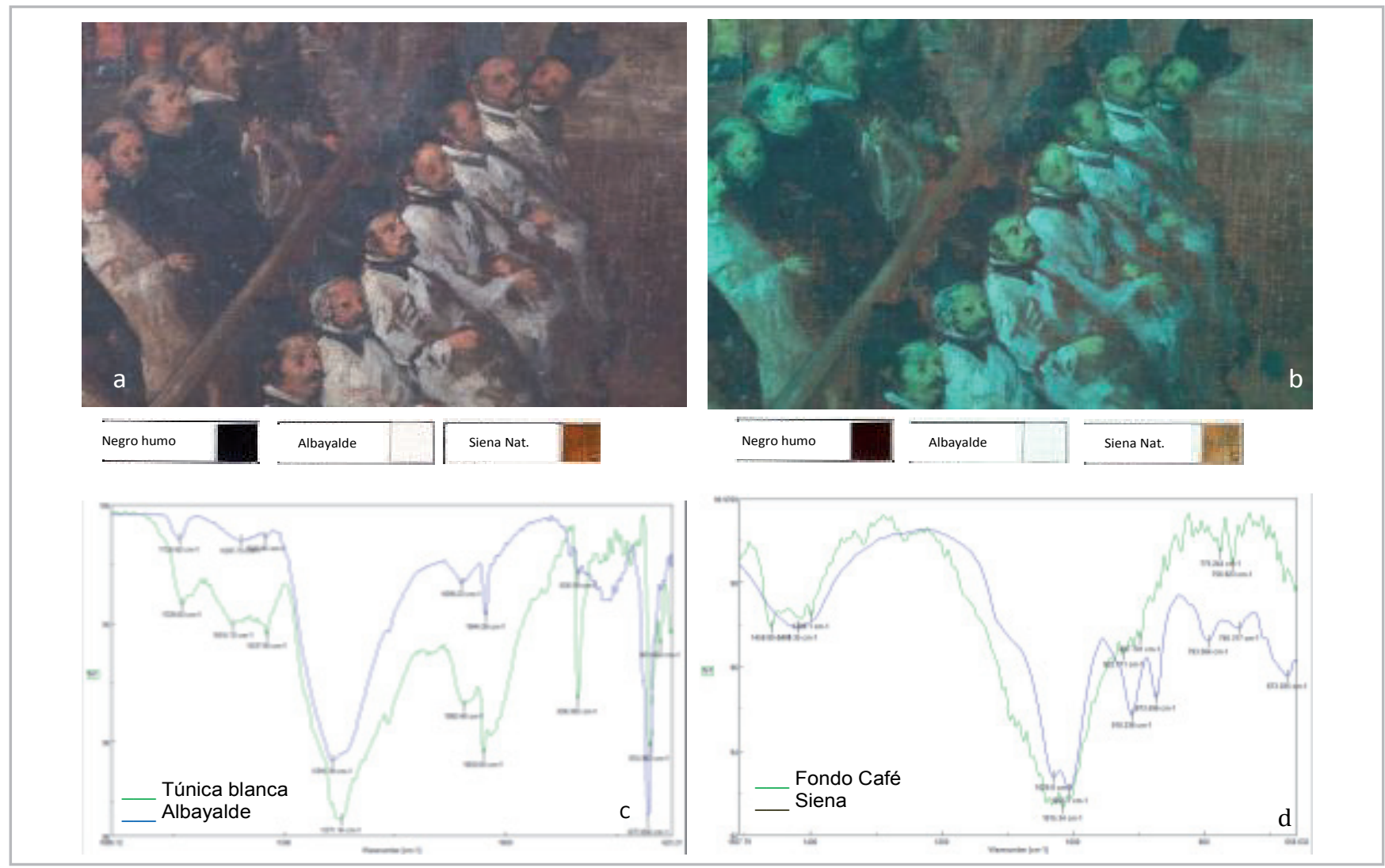

Figura 5.-Detalle, a) Imágenes de sacerdotes con VIS, b) Imágenes de sacerdotes IRFC, c) Espectro FTIR-ATR de la túnica blanca vs estándar de albayalde, d) Espectro FTIR-ATR de la muestra de fondo vs estándar de siena natural . Autores: Fernando Espinoza, Michelle Mármol y Carlos Vásquez, INPC. 
sobre una imprimación color café rojizo, en el que se sobreponen capas pictóricas de varios tonos opacos de ocre, trabajadas a partir de mezclas de blanco de plomo, ocre y masicote; que fueron aplicadas con pinceladas que aportan a la morfología y sirven como base cromática o fondo tonal en la elaboración de los elementos que conforman el retablo. Para ello hizo uso de pinceles de cerda y con poca carga de material, logrando pinceladas que dejan ver la textura y el color de la imprimación. Terminó con la sobreposición de capas de laca de gualda, aplicadas con pincel de pelo suave para conseguir capas lisas, finas, translúcidas y uniformes a modo de veladuras, logrando por transparencia cambios cromáticos de los tonos amarillos subyacentes. Este trabajo lo usó en la configuración de hornacinas, esculturas, molduras y demás elementos que ameritan ser representados con esta tonalidad amarillenta que imita el color del oro. El maestro de Santiago, también empleó las veladuras de gualda dispuestas directamente sobre la imprimación para obtener sombras y brillos sutiles de tono amarillo, que sirven para dar una ambientación luminosa particular a la zona del retablo [figura 7].

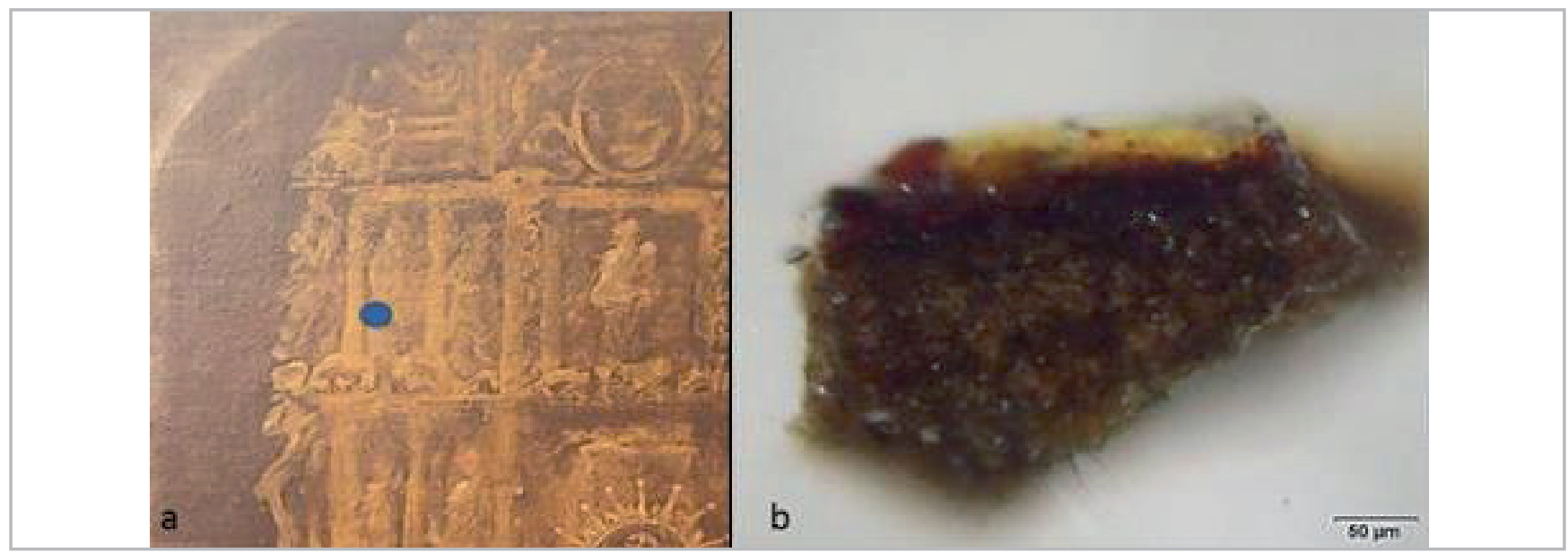

Figura 6.- Detalle, a) Retablo con VIS, b) Imagen sección transversal obtenida por M.O., del punto obtenido en el área señalada. Autores: Michelle Mármol y Carlos Vásquez, INPC.

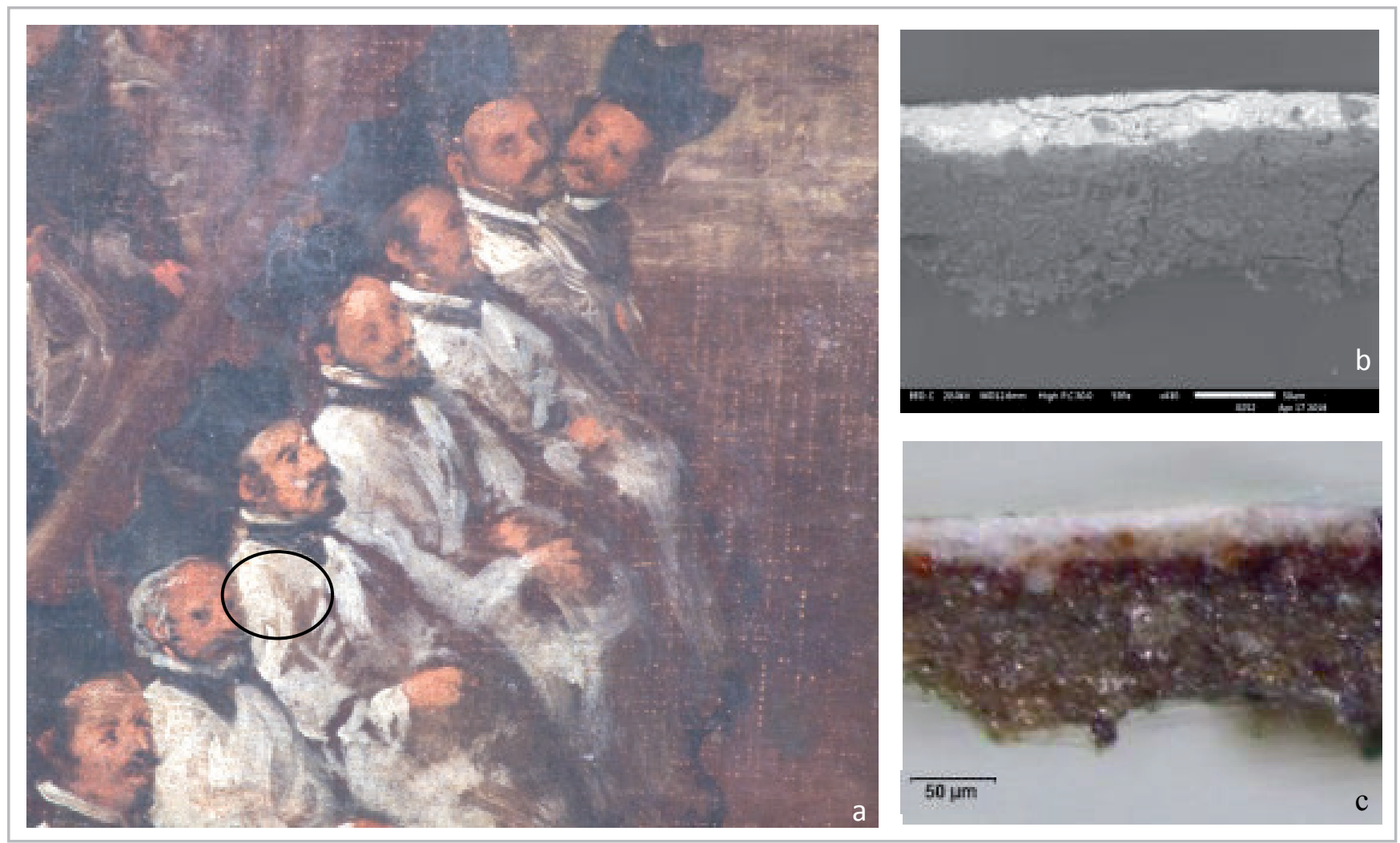

Figura 7.-Detalle, a) Imagen personajes con VIS, b) Imagen sección transversal del punto obtenido por MEB-EDX en el área señalada, c) Imagen sección transversal obtenida por M.O., del punto obtenido en el área señalada. Autores: Fernando Espinoza, Michelle Mármol y Carlos Vásquez, INPC. 
Resulta sugestivo como Miguel de Santiago logró una variada gama de tonos grises que le aportan a la configuración de los pliegues de las vestimentas de color claro, a partir de distintas modulaciones en los trazos para la aplicación de capas delgadas semitraslúcidas compuestas de blanco de plomo matizado con un poco de masicote, sobrepuestas al fondo café rojizo oscuro seco, que aporta con su tono. El trabajo de sombras y luces lo complementó con la aplicación de una capa de negro de humo para conseguir los efectos cromáticos claros, neutros y oscuros necesarios para representar la volumetría de los pliegues; y el empleó de veladuras de carmín de tonalidad rosa y lacas de gualda de tonalidad amarillo para la armonización las zonas de iluminación.

Para la elaboración de los encarnes, el maestro colocó pinceladas de color gris producto de una mezcla de blanco de plomo, masicote y negro de humo, en capas delgadas y semitraslúcidas que sirven como fondo y configuración inicial de los personajes. Continuaba con la colocación de pinceladas de una mezcla de blanco de plomo con cinabrio, minio y ocre rojizo en cantidades dosificadas según la necesidad de interpretación de la luz en los rostros; en general, estas capas eran más empastadas dejando en el trazo la huella el recorrido del pincel. Como parte de una etapa intermedia, integraba trazos con mezclas con cinabrio y blanco de plomo para la interpretación de rubores, cromática que es complementada en una fase final con la sobre posición de capas finas y traslúcidas de veladuras de carmín para intensificar el color en ciertas zonas [figura 8]. Así mismo, en este momento hizo uso del cinabrio/ bermellón en forma puntual para resaltar la coloración rojiza en los sectores de interpretación de brillo en rostros y manos.

Es evidente que en esta obra convergen un alto grado de conocimiento de la forma, la anatomía, el manejo de los materiales y la interpretación de la luz. Manifestados en una técnica privativa, en la que desde sus inicios prima la mancha de color, trazos con mezclas y formas particulares de aplicación, acorde a la morfología y a la dirección de la luz. Son también visibles la destreza en la ejecución de las pinceladas, el trabajo por sesiones que determinan la técnica de húmedo sobre seco empleada para evitar la mezcla de color en la pincelada, provoca mezclas ópticas por efecto del color subyacente, la sobreposición de capas con bajo nivel de opacidad y el uso de las veladuras que aportan particularmente al entorno cromático, logrando gran calidad en la representación a partir de procesos de simplificados.

Aparte de develar las secuencias de acciones seguidas por el maestro, también vamos a adentrarnos en otros significados técnicos y culturales implicados en el uso de estos materiales, pongamos por caso la calidad de los materiales usados por Miguel de Santiago en la ejecución de esta obra. Según tratadistas como Palomino incluye a nueve de los diez pigmentos identificados en la obra como colores "Precisos y usuales", por ser conocidos, empleados y presentes en las paletas de los pintores españoles e incluso europeos. (Palomino de Castro y Velasco 1796).

En referencia al coste de los materiales pictóricos, Palomino y Pacheco destacan el elevado coste de la gualda por su textura fina y delgada, el bermellón por ser uno de los colores más exquisitos, el carmín como uno de los colore finos, delgados y subidos; y el minio. Plinio los clasificó como "los floridos y más costosos". Según estos tratadistas, eran proporcionados por el cliente del encargo, mientras que el resto los aportaba el propio pintor; y estaban destinados a las obras y encargos de mayor prestigio. (Palomino de Castro y Velasco 1796; Pacheco 1866).

Otro aspecto relevante para revisar es el nivel de complejidad de las secuencias técnicas del arte de pintar, los tratadistas antes mencionados cuentan con
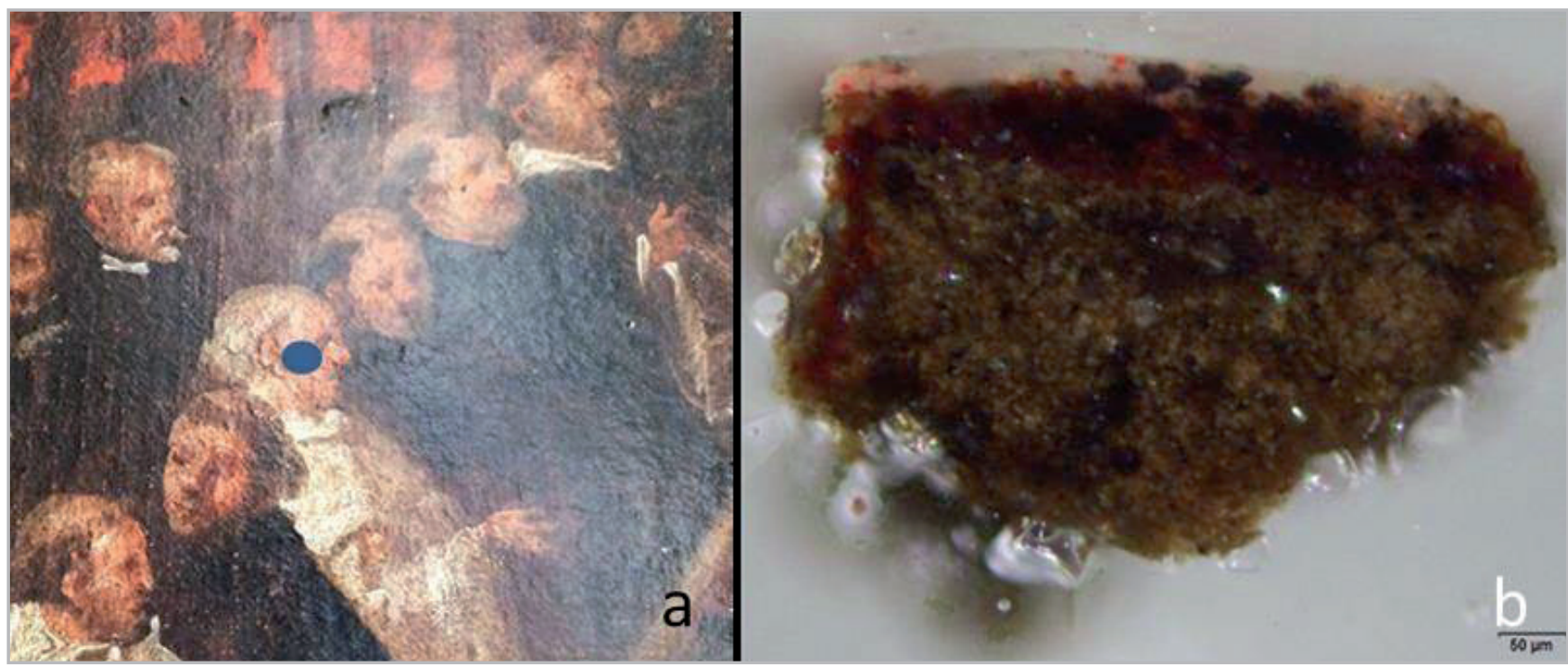

Figura 8.- a) Sitio de muestreo. b) Corte transversal donde se observa superposición de estratos. Autor: Michelle Mármol, INPC. 
poco o mucho detalle los procesos involucrados en la preparación de los materiales pictóricos. Como ejemplo nos centraremos en los modos de conservación o almacenamiento, que no eran iguales para todos los pigmentos y colorantes. Mencionan que el blanco de plomo, el masicote, el bermellón y el ocre se conservan en agua, mientras que otros no, como el carmín, la gualda y el negro de carbón. Incluso indican que los recipientes para guardar estos pigmentos tenían procesos de fabricación diferente, ya que si no se seguía estos pasos, las propiedades del pigmentos se perderían al secarse. Esto conduce a imaginar el taller de Miguel de Santiago, como un espacio de desarrollo, enseñanza y difusión de conocimientos empíricos, organizado en concordancia con las secuencias de elecciones y de operaciones fijadas por las reglas del arte en niveles diferenciados de complejidad, donde el Maestro a partir del conocimiento adquirido, destrezas y habilidades consiguió mejorar las técnicas por medio de la experimentación.

\section{Consideraciones finales}

Este artículo pone a consideración un enfoque trandisciplinario y multidimensional donde convergen las ciencias sociales y experimentales para abordar el estudio de la materialidad e inmaterialidad de una obra de arte, desde el principio de incompletud e incertidumbre. Así como también una metodología multianalítica, eficiente y eficaz para elucidar gran parte de los materiales y recursos técnicos pictóricos involucrados en su producción.

En un primer acercamiento a la obra "Milagro de la Virgen de Guápulo en su Santuario" desde esta perspectiva y aplicando esta metodología, permitió entender el lenguaje simbólico de estratificación social de la época, determinar que los materiales empleados son de alta calidad y costo e identificar que el maestro al cual le encargan la ejecución, fue uno de los pintores más reconocidos y estimados por la sociedad quiteña, lo cual, pone de manifiesto el prestigio y dignidad de la obra, de la ceremonia, de los personajes en ella representados y de los comitentes que encargaron su elaboración.

Y si a este detalle se suma que además el personaje central incorporado como la endemoniada, también constituye una imagen que se colocó allí en fecha posterior a la concepción y hechura del cuadro, ya que las gradas que conducen al altar no se ven interrumpidas para la colocación del personaje, que se presenta sobre las mismas, nos lleva a deducir la intencional utilización posterior de la obra, que puede obedecer a una nueva oportunidad de manejo de la imagen ante importantes crisis sociales que enfrentó posteriormente la Audiencia.

Al buscar acercarnos a la fecha de manufactura de la obra, hemos encontrado imprecisión en la cita de los acontecimientos respecto a las autoridades mencionadas, ya que estas comienzan a ejercer sus funciones el año de
1647 y no el año de 1646 como reza en la leyenda al pie de la obra; lo que nos lleva a considerar la existencia de una discordancia entre el título de la obra y la narrativa representada, que abre paso a futuras investigaciones.

\section{Notas}

[1] Dentro de la tabla de pigmentos estándar no se encuentra con exactitud un patrón de gualda, para recabar esta información se buscó bibliográficamente semejanzas entre colorantes orgánicos disponibles. Se comparó por medio de sustancias de referencia y se concluyó que los xantatos del Gamboge y los flavonoides de la Gualda son cromáticamente iguales tanto en imagen visible como en infrarrojo falso color.

[2] "En el año de 1646 en presencia del Sr. Obispo Don Agustín Duarte y el presidente Don Martín de Arriola llegó una india endemoniada estando en la misa mayor....."

\section{Referencias}

BARBU, O-H. ZAHARIADE, A. (2016). Noninvasive in situ study of pigments in artworks by means of VIS, IRFC image analysis, and $X$ ray fluorescence spectrometry: https://doi.org/10.1002/ col.22038

BENJAMIN, W. (1936). La obra de arte en la época de su reproductibilidad técnica. Berlin: RLull.

CARBÓ, M.; REIG, F.; ADELANTADO, J. et al. (1996). "Fourier transform infrared spectroscopy and the analytical study of works of art for purposes of diagnosis and conservation", en: Analytica Chimica Acta. https://doi.org/10.1016/0003-2670(96)00177-8.

CENNINI, C. (1988). El libro del Arte. Madrid: AKAL.

CHACÓN ZAPAN, J. (1986). Historia de la minería en Cuenca Juan Chacón Z. Cuenca. Universidad de Cuenca: Instituto de Investigaciones Sociales.

COSENTINO, A. (2013). "A Practical Guide to Panoramic Multispectral Imaging", en Cultural Heritage Science Open Source Scientific Examination for Art and Archaeology - Conservation and Authentication. http://chsopensource.org/panoramic\%20 multispectral\%20imaging.pdf.

DE LA PUERTA, R. (2008). “La moda civil en la España del siglo XVII inmovilismo e influencias extranjeras", en Ars longa: cuadernos de arte, 17: 77-85. http://roderic.uv.es/handle/10550/28302. [ consulta: 5/3/2019]

DIAZ, R. (2017). "La Imagen de la Virgen María con advocación de la Merced y su culto local en Portoviejo", Quito: Instituto Nacional de Patrimonio Cultural del Ecuador.

DOLEŻYŃSKA-SEWERNIAK, E \& KLISIŃSKA-KOPACZ, A. (2019). A characterization of the palette of Rafał Hadziewicz (1803-1886) 
through the following techniques: Infrared false colour (IRFC), XRF, FTIR, RS and SEM-EDS, en Journal of Cultural Heritage 36: 238-246. https://doi.org/10.1016/j.culher.2018.09.001

DURAN, A. etal. (2010).“Murillo's paintings revealed by spectroscopic techniques and dedicated laboratory-made micro X-ray diffraction", en Analytica Chimica Acta, 671(1-2): 1-8: https://doi.org/10.1016/j. aca.2010.05.004 [ consulta: 25/01/2021]

ESTEBARANZ, Á. J. (2011). Pintura y sociedad en Quito en el siglo XVII. Quito: Pontificia Univ. Católica del Ecuador.

ESTEBARANZ, Á. J. (2013). El pintor quiteño Miguel de Santiago (16331706), su vida, su obra y su taller. Sevilla: Universidad de Sevilla.

GALLI, A. et al. (2020). "Imaging and spectroscopic data combined to disclose the painting techniques and materials in the fifteenth century Leonardo atelier in Milan", en Dyes and Pigments 187 https:// doi.org/10.1016/j.dyepig.2020.109112 [consulta: 25/01/2021]

GARGANO, M. et al. (2020). "Multi-analytical investigation of panel, pigments and varnish of The Martyirdom of St. Catherine by Gaudenzio Ferrari (16th century)", en Journal of Cultural Heritage, 46: 289-297, https://doi.org/10.1016/j.culher.2020.06.014 [consulta: 25/01/2021]

HAUSER, A. (1974). Sociologia del Arte. Guadarrama. https://www. academia.edu/14950675/Arnold Hauser Sociologia del Arte [ consulta: $25 / 01 / 2021]$

IACOPO, O. et al (2020). "Argento Deaurato" or "Argento Biancheggiato"? A Rare and Interesting Case of Silver Background in Italian Painting of the XIII Century, en Appl. Sci. 2020, 10(7), 2404; https://doi.org/10.3390/app10072404 . [ consulta: 14/12/2020]

LA RUSSA, M. F. et al. (2009). "The Use of FTIR and MicroFTIR Spectroscopy: An Example of Application to Cultural Heritage", en: International Journal of Spectroscopy, https://doi. org/10.1155/2009/893528 [ consulta: 25/01/2021]

LEMONNIER, P. (1992). Elements for an Anthropology of Technology. Anthropological Papers Series. Michigan: University of Michigan, Museum of Anthropology, Publications Department.

MATTEINI, M., MOLES A. (2001). "La química en la restauración". Donostia San Sebastian: NEREA.

MORIN, E. (1990). "Introducción al pensamiento complejo". Cladema. https://norberto2016.files.wordpress.com/2016/10/morinedgar introduccion-al-pensamiento-complejo parte1.pdf. [consulta: 25/01/2021]

PACHECO, F. (1649). "Arte de la pintura, su antigüedad y grandeza". https://books.google.com.ec/books?id=litPAAAAYAAJ\&printsec=fr ontcover $\& h l=e s \&$ source $=g b s$ ge summary $r \& c a d=0 \# v=$ onepage \&q\&f=false. [consulta: 8/3/2019]

PALET I CASAS, A. (2002). "Tratado de pintura: color, pigmentos y ensayo". Barcelona: Edicions Universitat de Barcelona.
PALOMINO DE CASTRO Y VELASCO, A. (1796-1797). "El museo pictorico y escala optica : practica de la pintura, en que se trata de el modo de Pintar a el Oleo, Temple, y ... / por Don Antonio Palomino Velasco"; tomo segundo". 2a ed. 1796-1797, Biblioteca Virtual Andalucía. http://www.bibliotecavirtualdeandalucia.es/catalogo/ es/consulta/registro.cmd?id=7373 [consulta: $24 / 3 / 2019$ ]

PARRILLA, M. A. (2009). “El arte de los pigmentos. Análisis históricoartístico de su evolución a partir de los tratados españoles de Francisco Pacheco y Antonio Palomino", Tesis doctoral, Universidad de Valencia. Servei de Publicacions. http://hdl.handle. net/10803/9974

PONCE, P. (1992). “Relación de la ciudad y provincia de Quito (157071). Salazar de Villasante, Lic, (1570-71)". Quito: Abya Yala.

ROMERO, M. \& SÁNCHEZ POLO, A., 2018. “Pigmentos y Brillos, En la Costa del Ecuador Precolombino". Quito: La Caracola Editores.

SALGADO GÓMEZ, M. (1997). “La Imagen de María. La Historia de una Imagen, Tesis de Maestría en Historia", Quito: Flacso.

SIRACUSANO, G. (2005). "El poder de los colores. De lo material a lo simbólico en las prácticas culturales andinas. Siglos XVI-XVIII". Buenos Aires: Fondo de Cultura Económica.

TEKE, M. BAŞESKI, E., ÖZGÜN OK, A. et al. (2011). "Multi-spectral False Color Shadow Detection". Lecture Notes in Computer Science, vol 6952. Springer, Berlin: Heidelberg. https://doi.org/10.1007/978-3642-24393-6 10 [ consulta: 9/3/2019]

VARGAS, J. M. (1959). "Historia de la Cultura Ecuatoriana". En Fundación Biblioteca Virtual Miguel de Cervantes: http:// www.cervantesvirtual.com/obra-visor/historia-de-la-culturaecuatoriana--0/html/0027fcd4-82b2-11df-acc7-002185ce6064 21. html. [ consulta: 13/3/2019]

WEBSTER, S. V. (2016). “Materiales, modelos y mercado de la pintura en Quito, 1550-1650". Procesos, I(43): 37-64.

WEBSTER, S. V. (2017). "Lettered Artist and the languages of empire. Painters and the Profession in Early Colonial Quito". Austin: University of Texas Press.

\section{Autor/es}

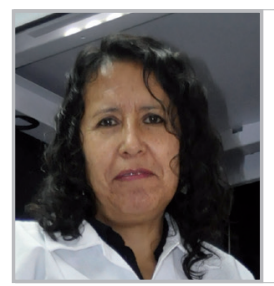

Martha Elizabeth Romero

laboratorioinpc@gmail.com

Instituto Nacional de Patrimonio Cultural del Ecuador

Formación profesional en las ciencias experimentales y las ciencias sociales a las que se aproximó a partir de mis estudios de maestría. En los últimos años ha trabajado fundamentalmente en la caracterización de materiales de bienes culturales a través del uso 
de técnicas analíticas como difracción de rayos $\mathrm{X}$ y microscopía electrónica de barrido, orientada al estudio de las técnicas de producción y los procesos de deterioro.

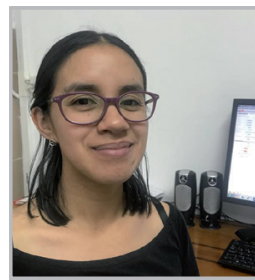

\section{Michelle Carolina Mármo}

michelle.marmol@patrimoniocultural.gob. ec

Instituto Nacional de Patrimonio Cultural del Ecuador

Investigadora Química, se ha formado en las bases de las diferentes técnicas analíticas orientadas al estudio de bienes patrimoniales. Lleva tres años trabajando como investigadora en el laboratorio especializandose en la caracterización de materiales a través de análisis microquímicos, microscopía óptica y electrónica, y fluorescencia de rayos $\mathrm{X}$. Ha trabajado en policromía de pintura caballete, mural y escultura, así como otro tipo de soportes como son papel, piedra y metales.

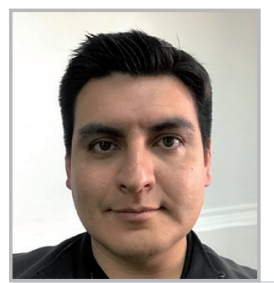

\section{Carlos Andrés Vásquez}

carlos.vasquez@patrimoniocultural.gob.ec Instituto Nacional de Patrimonio Cultural del Ecuador

Investigador Químico durante 8 años y, 7 de ellos en el ámbito de patrimonio cultural. Su especialidad es la caracterización de materiales de origen orgánico en soportes papel, pintura, policromía y análisis microbiológico de bienes culturales. Ha trabajado también en la aplicación de nuevas tecnologías digitales de imagen a través del uso de reflectografía infrarroja y análisis de imagen multiespectral.

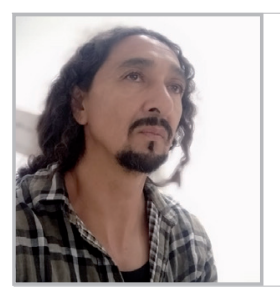

\section{Fernando Espinoza Guerra}

fernando.espinoza@patrimoniocultural. gob.ec

Restaurador y artista plástico con manejo de diferentes técnicas tradicionales en escultura, pintura, grabado, orfebrería y cerámica. Vinculado a la investigación para la conservación y puesta en valor del patrimonio cultural en la Unidad de Laboratorio y Análisis del Instituto Nacional de Patrimonio Cultural. Director de proyecto Senescyt para la puesta en valor de las técnicas tradicionales y ancestrales para la producción cerámica, también ha participado como miembro de equipo técnico en diferentes proyectos para caracterización, diagnóstico y conservación de material cultural: Material pétreo en Capac Ñan, monumento arqueológico de Ingapirca, caracterización de tecnología de producción de objetos culturales metálicos y estudio de los recursos técnico pictóricos empleados en la generación de imagen en la obra de Miguel de Santiago.

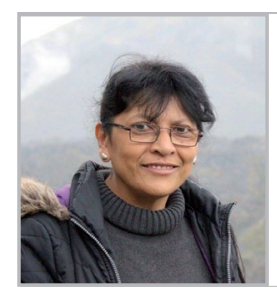

\section{Rita del Consuelo Díaz}

rita.diaz@patrimoniocultural.gob.ec Instituto Nacional de Patrimonio Cultural del Ecuador

Por espacio de 25 años ha desempeñado su actividad como historiadora del Instituto Nacional de Patrimonio Cultural, dirigiendo y colaborando en más de 100 investigaciones de bienes patrimoniales muebles, inmuebles e inmateriales. Durante los últimos 7 años ha formado parte del contingente interdisciplinario de la Unidad de Investigación y Análisis del INPC participando fundamentalmente en proyectos de investigación de caracterización de materiales de bienes culturales para la conservación, autentificación y puesta en valor del Patrimonio cultural del Ecuador.

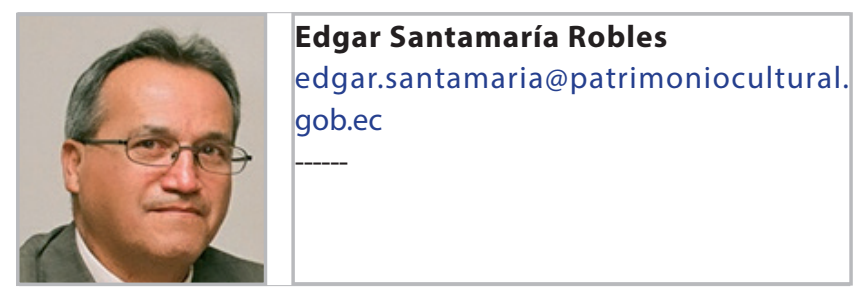

Restaurador de Obras de Arte con especialización en Escultura Policromada en el Instituto Real de Patrimonio Artístico IRPA en Bruselas, Bélgica. Participó en la Conservación, Restauración y Puesta en Valor del Proyecto Bilateral ECUABEL (Ecuador-Bélgica) del convento de Santo Domingo de la ciudad de Quito. Responsable del Proyecto de Conservación, Restauración y Puesta en Valor del Museo santa Catalina de Siena del Monasterio del mismo nombre en la ciudad de Quito. Conservador y Restaurador en la colección de la Fundación Oswaldo Guayasamín. Inspector de Bienes Culturales de la Dirección de Tráfico llícito e Investigador de la Dirección de Investigación e Innovación del Instituto Nacional de Patrimonio Cultural del Ecuador INPC. Al momento participa junto a un equipo multidisciplinario de investigadores del INPC en la caracterización de obras de pintores ecuatorianos, especialmente en el área de análisis Multiespectrales, análisis de fibras, estados de conservación, estudios iconográficos, estudios estilísticos y de composición artística de Bienes Culturales.
Artículo enviado el 11/01/2020 Artículo aceptado el 21/05/2021

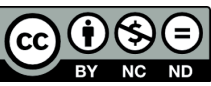

https://doi.org/10.37558/gec.v19i.728 